\title{
Relation between the ankle-brachial index and the complexity of coronary artery disease in older patients
}

This article was published in the following Dove Press journal:

Clinical Interventions in Aging

29 November 2013

Number of times this article has been viewed

\author{
Felipe José de Andrade \\ Falcão' \\ Cláudia Maria Rodrigues \\ Alves' \\ Adriano Caixeta' \\ Leonardo de Freitas \\ Guimarães' \\ Juscélio Trajano de Sousa \\ Filho $^{2}$ \\ Juliana A Soares ${ }^{2}$ \\ Izo Helber ${ }^{2}$ \\ Antônio C Carvalho' \\ 'Department of Interventional \\ Cardiology, ${ }^{2}$ Department of Cardiology, \\ Federal University of São Paulo, \\ São Paulo, Brazil
}

Correspondence: Felipe José de Andrade Falcão

Rua Isaac Salazar 102/902, Recife,

Pernambuco, Brazil

Tel +55 87992 I 6886

Email felipejaf@gmail.com
Background: In the elderly, the ankle-brachial index (ABI) has greater than $90 \%$ sensitivity and specificity for peripheral artery disease identification. A well-known relation exists between peripheral artery disease and the number of diseased coronary vessels. Yet, other anatomical characteristics have important impacts on the type of treatment and prognosis.

Purpose: To determine the relation between ABI and the complexity of coronary artery disease, by different anatomical classifications.

Methods: This study was a prospective analysis of patients $\geq 65$ years old who were undergoing elective coronary angiography for ischemic coronary disease. The ABI was calculated for each leg, as the ratio between the lowest ankle pressure and the highest brachial pressure. The analysis of coronary anatomy was performed by three interventional cardiologists; it included classification of each lesion with $>50 \%$ diameter stenosis, according to the American Heart Association criteria, and calculation of the SYNTAX score.

Results: The study recruited 204 consecutive patients (median age: 72.5 years). Stable angina was present in $51 \%$ of patients. Although only $1 \%$ of patients reported peripheral artery disease, $45 \%$ exhibited an abnormal ABI. The number of lesions per patient, the number of patients with complex lesions, and the median SYNTAX scores were greater in the group with abnormal ABI. However, among 144 patients with obstructive coronary artery disease, despite abnormal ABI being able to identify a higher rate of patients with $\mathrm{B} 2$ or $\mathrm{C}$ type lesions $(70.9 \%$ versus $53.8 \%$; $P=0.039$ ), the mean SYNTAX scores (13 versus $9 ; P=0.14$ ), and the proportion of patients with SYNTAX score $>16(34.2 \%$ versus $27.7 \% ; P=0.47)$, were similar, irrespective of ABI.

Conclusion: In patients $\geq 65$ years old the presence of peripheral artery disease could discriminate a group of patients with greater occurrence of B2 and C type lesions, but similar median SYNTAX score.

Keywords: ankle-brachial index, coronary artery disease, peripheral artery disease, elderly health

\section{Introduction}

Peripheral artery disease (PAD) is an important marker of cardiovascular morbidity and mortality, with prevalence that increases progressively with age. The prevalence of PAD ranges from $1 \%-3 \%$, in the fourth or fifth decade of life, to greater than $20 \%$ in the eighth decade. ${ }^{1,2}$ The ankle-brachial index (ABI), which is a noninvasive and inexpensive measurement used to identify PAD in the elderly population, has remarkably high sensitivity and specificity ( $>90 \%$, for each), compared against invasive angiography. ${ }^{3}$

$\mathrm{ABI}$, as a marker of PAD, has been widely used to predict coronary artery disease (CAD). ${ }^{1,4-8}$ Moreover, obstructive atherosclerotic lesions in at least one coronary 
artery have been reported in $60 \%-80 \%$ of patients with PAD who had undergone cardiac catheterization. ${ }^{9}$ These patients had more extensive and calcified lesions, suggesting a more aggressive form of atherosclerosis. ${ }^{10-12}$

The anatomical complexity of CAD, and the number of vessels affected, influence the type of treatment that is offered to patients, and have an impact on short- and long-term prognosis. In recent years, the need for objective measurements to identify CAD has spurred the development of several angiographic scores. ${ }^{13-15}$ Over the last few years, the SYNTAX score (SS) has become the most widely used angiographic score, because it can guide the most appropriate type of revascularization (percutaneous or surgical) for each individual, and it also provides prognostic information for mid-term follow-up after revascularization. ${ }^{16}$

This study aimed to report a detailed description of coronary anatomical markers in older patients, with and without PAD, and to compare the results with published data on general populations.

\section{Methods}

We performed a single-center prospective cross-sectional study. The study recruited patients $\geq 65$ years old who had been admitted to The Federal University of São Paulo consecutively between September 2011 and July 2012 for coronary angiography for ischemic coronary disease (silent ischemia, stable angina, or acute coronary syndromes [ACS] without ST segment elevation). Patients were excluded if they had ACS with ST elevation, creatinine clearance of $\leq 30 \mathrm{~mL}$ per minute, or if blood pressure could not be measured in one limb, for any reason. Patients were included in the study after signing an informed consent form. This study was approved by the institutional review board of the Federal University of São Paulo, Brazil (Study number: CEP 1299/11).

ABI was measured immediately before coronary angiography. After the patient had rested for at least 5 minutes in a supine position, measurement was performed using a portable ultrasound Doppler (DV 610B; Medmega ${ }^{\circledR}$, São Paulo, Brazil) and an Innova aneroid sphygmomanometer (BIC ${ }^{\circledR}$, São Paulo, Brazil), with cuff inflators appropriate for brachial circumference. Systolic blood pressure measurements of the brachial, tibial posterior, and dorsalis pedis arteries were taken on both sides of the limb. ABI was calculated as the ratio between the lowest ankle systolic pressure and the highest brachial systolic pressure. ${ }^{17,18} \mathrm{ABI}$ was determined for each leg, and the lowest value was considered for analysis. The patients were divided into two groups, according to
$\mathrm{ABI}$ (Group 1: $\mathrm{ABI} \leq 0.9$; Group 2 [normal]: $\mathrm{ABI}>0.9$ ). Although $\mathrm{ABI}>1.3$ is considered abnormal, none of our patients reached this value.

Coronary angiography was performed using conventional techniques, and analyzed by three experienced interventional cardiologists, who were blinded to clinical data. Consensus was required between at least two of them. CAD was defined as single vessel or multivessel disease, according to the number of epicardial arteries with at least one lesion measuring $\geq 50 \%$ diameter stenosis. Each coronary lesion measuring $\geq 50 \%$ diameter stenosis was classified according to its complexity into types A, B1 (one type B characteristic), B2 (two or more type B characteristics), or C, according to the criteria of the American Heart Association. This classification is based on success rates for the percutaneous approach, with lower success rates reported for B2 and C type lesions. ${ }^{19}$

\section{Calculation of the SYNTAX score}

The SS evaluates stenosis that has caused a reduction of more than $50 \%$ in luminal diameter, in vessels of $1.5 \mathrm{~mm}$ or larger diameter. The number and extent of lesions, the tortuosity of the affected segments, the presence of thrombus or calcification, total occlusion, and involvement of bifurcation or trifurcation were evaluated. The lesions to be considered for analysis were identified and selected by consensus. Each selected lesion was then scored, according to its complexity. The SS is the sum of the individual scores for each lesion, and was calculated using SYNTAX Score Calculator software version 2.11 (SYNTAX Score Working Group, www.syntaxscore.com).

In the Syntax Trial, ${ }^{16}$ the study which was responsible for development of the SS, only patients with three-vessel or left main CAD were included, resulting in terciles with high values, compared with "all comers" studies. Nevertheless, these values are widely used as a tool to choose between surgical ( $S S \geq 33$ ) or percutaneous ( $S S<22$ ) revascularization. Studies that include patients with one- and two-vessel disease provide a more appropriate, "real world" sample population, and yield terciles that compare appropriately to our group. At least two large trials included patients with stable and unstable coronary syndromes, allowing for proper comparison; both yielded similar tercile levels, with patients in the highest level having SS $>16 .{ }^{20,21}$ One study, which included only patients with non-ST elevation ACS, yielded slightly lower tercile and average values. ${ }^{22}$ These studies have demonstrated the value of the SS, as a prognostic tool for mid-term follow-up; the higher the SYNTAX Score, the greater the risk for late events after revascularization. ${ }^{16,20-22}$ Next, we compared the rates for SS $>33$, and SS $>16$, in 
our population, and whether there was accordance with ABI results.

\section{Statistical analysis}

Continuous variables were expressed as means with standard deviations, or as medians with 25 th and 75 th percentiles, according to the presence or absence of a normal distribution, as determined by the Kolmogorov-Smirnov test. The MannWhitney test and Student's $t$-test were used for analyzing continuous variables, in accordance with the distribution. Categorical variables were expressed as absolute numbers with percentages. Fisher's exact test, or the chi-square test, was used for categorical variables.

A multivariable logistic regression model was used to identify potential independent predictors of $\mathrm{CAD}$, multivessel disease, and the presence of B2 or C type lesions in the overall population. Odds ratios (OR) and their respective $95 \%$ confidence intervals (CI) were used to quantify the analyses. The variables included in the model were: age, sex, hypertension, dyslipidemia, diabetes mellitus, smoking status, and ABI measurement. SPSS ${ }^{\circledR}$ version 20.0 statistical software (IBM Corp, Armonk, NY, USA) was used for all analyses. A final $P$-value of less than 0.05 was considered significant.

\section{Results}

A total of 204 patients were recruited, with a median age of 72.5 years (interquartile range: $68-77$ years). Although only $1 \%$ of patients reported PAD, $45 \%$ had an abnormal ABI. None showed an ABI greater than 1.3. We observed a higher number of female patients, and patients with ACS, in Group 1 (patients with abnormal ABI of $\leq 0.9$ ). Other clinical characteristics are summarized in Table 1 . ABI had a sensitivity of $76.7 \%$, and a specificity of $55 \%$, for predicting obstructive CAD, with an efficacy similar to the treadmill test. ${ }^{23}$

Table I Clinical characteristics of the patients in each group

\begin{tabular}{|c|c|c|c|}
\hline \multirow[t]{2}{*}{ Variables } & \multicolumn{2}{|c|}{ Total sample: 204 ( $100 \%)$} & \multirow[t]{2}{*}{ P-value } \\
\hline & $\begin{array}{l}\text { Group I } \\
A B \mid \leq 0.9 \\
(N=93)\end{array}$ & $\begin{array}{l}\text { Group } 2 \\
A B \mid>0.9 \\
(N=|| I)\end{array}$ & \\
\hline$\left.A B\right|^{\mathrm{a}}$ & $0.73(0.57-0.8 I)$ & $1.03(0.98-1.10)$ & NA \\
\hline Age $^{a}$ (years) & 74 (69-78) & 7I (67-76) & 0.057 \\
\hline Female sex & $53(56.9 \%)$ & 46 (4I.4\%) & 0.027 \\
\hline Systemic hypertension & 86 (92.4\%) & 98 (88.2\%) & 0.317 \\
\hline Diabetes mellitus & $36(38.7 \%)$ & $36(32.4 \%)$ & 0.35 \\
\hline Dyslipidemia & $50(53.7 \%)$ & $59(53.1 \%)$ & 0.931 \\
\hline Smoking & 33 (35.4\%) & $26(23.4 \%)$ & 0.058 \\
\hline $\begin{array}{l}\text { Acute coronary } \\
\text { syndrome }\end{array}$ & $64(68.8 \%)$ & $36(32.4 \%)$ & 0.0001 \\
\hline
\end{tabular}

Note: ${ }^{\vee}$ Values expressed as median and interquartile range. Abbreviations: $\mathrm{ABI}$, ankle-brachial index; NA, not applicable.
In the overall study population, ABI of $\leq 0.9$ was strongly associated with the presence of CAD (OR $=2.43$; CI: $1.47-4.03 ; P=0.0001)$. Patients in Group 1 more often exhibited multivessel disease $(\mathrm{OR}=2.63$; $\mathrm{CI}$ : 1.48-4.67; $P=0.001)$ and $\mathrm{B} 2$ or $\mathrm{C}$ type lesions (OR =3.28; CI: 1.84-5.85; $P=0.0001$ ), compared with those in Group 2. The median SS in the general population was 7; it was significantly higher in Group 1 than in Group 2 (12 versus 3; $P<0.001$ ) (Table 2).

Obstructive CAD was observed in 144 patients $(70.6 \%)$. Of these, 79 patients $(54.8 \%$ ) had abnormal ABI values. The number of patients with multivessel disease was slightly greater $(66 \%$ versus $50 \% ; P=0.05)$, and rates of complex lesions (B2 or C type) were significantly higher $(70.9 \%$ versus $53.8 \% ; P=0.039$ ) in Group 1, compared with Group 2.

Considering only patients with obstructive coronary disease, median SS values and rates of SS $>16$ were similar in both groups (Table 3 ). Considering only patients with multivessel disease, the proportion of patients with $\mathrm{SS} \geq 33$ was only $8 \%$ among Group 1 , and was zero in Group $2(P=0.1)$.

\section{Discussion}

The risk of $\mathrm{CAD}$ can be estimated on the basis of multiple markers of atherosclerotic disease. Early identification of atherosclerosis, in any vascular bed, indicates high cardiac risk. Carotid intimal media thickening and high calcium scores, for example, have been associated with higher prevalence of CAD. ${ }^{24-26}$ More appropriate use of ABI to diagnose PAD has been well established in the literature. It has the benefit that it can be performed quickly by health care professionals, sparing advanced diagnostic methods. ${ }^{1,4-6}$ In a prospective study of 165 patients undergoing elective cardiac catheterization, ABI was correlated with the number of coronary vessels with obstructive lesions, and with the angiographic Gensini score. ${ }^{11}$ This relation also exists in patients undergoing cardiac

Table 2 Angiographic characteristics of patients in each group

\begin{tabular}{|c|c|c|c|}
\hline \multirow[t]{2}{*}{ Variables } & \multicolumn{2}{|c|}{ Total sample: 204 ( I 00\%) } & \multirow[t]{2}{*}{$P$-value } \\
\hline & $\begin{array}{l}\text { Group I } \\
A B \mid \leq 0.9 \\
(\mathrm{~N}=93)\end{array}$ & $\begin{array}{l}\text { Group } 2 \\
A B \mid>0.9 \\
(\mathbf{N}=|I|)\end{array}$ & \\
\hline Without CAD & 14 (I5\%) & $46(4 I .4 \%)$ & $<0.0001$ \\
\hline $\begin{array}{l}\text { Median number } \\
\text { of lesions per patient }\end{array}$ & $2(I-3)$ & I $(0-2)$ & $<0.0001$ \\
\hline Multivessel & $50(53.7 \%)$ & $34(30.6 \%)$ & 0.001 \\
\hline $\begin{array}{l}\text { Patients with B2- } \\
\text { or C-type lesions }\end{array}$ & $56(60.2 \%)$ & 35 (3I.5\%) & $<0.0001$ \\
\hline SYNTAX score & $12(5-17.5)$ & $3(0-12)$ & $<0.0001$ \\
\hline
\end{tabular}

Note: The figures for Median number of lesions per patient and SYNTAX score are expressed as median and interquartile range.

Abbreviations: $C A D$, coronary artery disease; $A B I$, ankle-brachial index. 
Table 3 Angiographic characteristics of patients with coronary artery disease

\begin{tabular}{|c|c|c|c|}
\hline \multirow[t]{2}{*}{ Variables } & \multicolumn{2}{|c|}{$\begin{array}{l}\text { Population with CAD: } \\
\text { I } 44(70.6 \%)\end{array}$} & \multirow[t]{2}{*}{$P$-value } \\
\hline & $\begin{array}{l}\text { Group I } \\
A B I \leq 0.9 \\
(\mathbf{N}=79)\end{array}$ & $\begin{array}{l}\text { Group } 2 \\
A B I>0.9 \\
(N=65)\end{array}$ & \\
\hline $\begin{array}{l}\text { Median number } \\
\text { of lesions per patient }\end{array}$ & $2(I-3)$ & $3(I-3)$ & 0.061 \\
\hline Left main involvement & $5(6.3 \%)$ & $3(4.6 \%)$ & 0.65 \\
\hline Multivessel & $50(63.2 \%)$ & $34(52.3 \%)$ & 0.23 \\
\hline $\begin{array}{l}\text { Patients with B2- } \\
\text { or C-type lesions }\end{array}$ & $56(70.8 \%)$ & $35(53.8 \%)$ & 0.039 \\
\hline SYNTAX score ${ }^{a}$ & $13(7-18)$ & $9(5-19.5)$ & 0.148 \\
\hline SYNTAX score $\geq 13^{b}$ & 47 (59.4\%) & 28 (43\%) & 0.04 \\
\hline SYNTAX score $>16^{c}$ & 27 (34.1\%) & $18(27.6 \%)$ & $0.47 I$ \\
\hline SYNTAX score $>17^{d}$ & $23(29.1 \%)$ & $18(27.6 \%)$ & 0.851 \\
\hline SYNTAX score $\geq 33^{\mathrm{e}}$ & $4(8 \%)$ & $0(0 \%)$ & 0.143 \\
\hline
\end{tabular}

Notes: aMedian SYNTAX score in the population with CAD = 12 (range: 5.25-18.75); bhighest tertile of SYNTAX score in Acute Catheterization and Urgent Intervention Triage Strategy (ACUITY) trial; chighest tertile of SYNTAX score in Limus Eluted from A Durable versus ERodable Stent coating (LEADERS) trial; 'highest tertile of SYNTAX score in RESOLUTE trial; ehighest tertile of SYNTAX score in Syntax Trial, including only patients with multivessel disease. The figures for Median number of lesions per patient and SYNTAX score are expressed as median and interquartile range. Abbreviations: $C A D$, coronary artery disease; $A B I$, ankle-brachial index.

catheterization on an urgent or emergency basis. In a multivariate analysis, pathological $\mathrm{ABI}$ was significantly associated with the risk of multivessel disease in patients with ACS (OR $=1.58$; CI: $1.16-2.15 ; P<0.05) .{ }^{12}$

Our study investigated the anatomic characteristics in a high-risk group (older than 65 years, and referred for coronary angiography) and included the ABI as a further indicator of atherosclerotic involvement. Our use of a more sensitive method for calculating ABI resulted in superior detection of CAD prevalence in Group 1; hence, $\mathrm{ABI}$ is a good discriminator for the presence and severity of disease in the older general population. Other trials have shown similar incidences of PAD in patients with CAD. ${ }^{27,28}$

Patients with and without abnormal ABI had similar demographic characteristics. However, the frequency of ACS was higher in patients with abnormal ABI ( $68 \%$ versus $32 \%$; $P=0.0001$ ). The presence of PAD, irrespective of the diagnostic criteria used, is related to an increased risk of developing ACS. The relative risk of myocardial infarction varies from 1.2 to 4.7 in several series. ${ }^{29-32} \mathrm{PAD}$ is a powerful predictor of cardiovascular events, even compared to the prior existence of $\mathrm{CAD}$ as a predictor. ${ }^{33}$ Moreover, the association of PAD and ACS increases by $60 \%$ the probability of progression to congestive heart failure. ${ }^{6}$

Suitable characterization of coronary anatomy is essential in the selection of a revascularization strategy (percutaneous or surgical), especially in high surgical risk groups. Evaluation of coronary complexity by the number of vessels involved (single or multivessel disease) is flawed; a patient may present various complex lesions in a single vessel, or have several lesions of low complexity, or without clinical significance, in multiple vessels. With the development of percutaneous intervention, which has allowed complex lesions to be treated with high success rates, the SS was created as a tool to quantify anatomical complexity, when percutaneous or surgical myocardial revascularization is being considered. In general, patients with high SS ( $\geq 33$ in multivessel disease, or $>16$ in non-3-vessel disease patients) have a greater risk of cardiovascular events after angioplasty, in comparison to events after surgery. ${ }^{16,22,34}$ Aside from evaluating the angiographic characteristics of each lesion, the SS also considers the proportion of ischemic myocardium that is at risk from stenosis. This is one reason that may explain the prognostic suitability of the SS, as higher scores correspond to larger ischemic areas.

Several previous reports showed a clear inverse relation between ABI and SS. Korkmaz et al, after evaluating 150 patients with ACS, irrespective of age, showed that patients with $\mathrm{ABI} \leq 0.9$ had a higher SS, compared with patients with ABI of $1.0-1.09(17.8 \pm 9.1$ versus $12.5 \pm 5.9 ; P<0.001){ }^{35}$ In a recent study, Ikeda et al selected 496 Asian coronary angiography patients, with a mean age of $69.2 \pm 11.4$ years, and compared ABI against SS. They reported mean values of SS similar to ours for the abnormal ABI group. ${ }^{36}$ However, an analysis was not performed for patients with CAD only. Benyakorn et al also demonstrated a significant negative correlation between $\mathrm{ABI}$ and SS, but theirs was a different population, which included a large proportion of patients with valvular disease, and included all age groups. ${ }^{37}$

Because of the higher surgical risk and the high frequency of comorbidities in elderly patients, percutaneous treatment is favored over surgical treatment. Therefore, the ability to closely predict coronary anatomy is important. In this series, with the first record of a correlation between $\mathrm{ABI}$ and the complexity of CAD in elderly patients, the use of the SS as a quantitation tool for the disease has also helped us to understand the context of medical practice by which angioplasty has been used more often in elderly patients. ${ }^{38}$ Once low rates (only $8 \%$ ) of high anatomic risk patients among those with multivessel disease are observed, the percutaneus intervention may be a good choice in a vast portion of this population.

In the present study, the statistical correlation between $\mathrm{ABI}$ and SS was lost when analyzing only patients with 
obstructive $\mathrm{CAD}$ ( 13 versus $9 ; P=0.148$ ), probably reflecting more extensive disease in the elderly in both groups. The similar frequencies, between groups, of patients with $\mathrm{SS}>16$, and $\mathrm{SS}>17$ (the last terciles of the Limus Eluted from A Durable versus ERodable Stent coating (LEADERS) ${ }^{20}$ and RESOLUTE $^{21}$ trials, respectively) may indicate a need to establish specific values for predict cardiac events in the elderly. Within the realms of modern percutaneous intervention, ABI did not identify in this population a subpopulation in which percutaneous revascularization could not be considered - particularly if we contemplate a scenario in which functional revascularization is accessible, and would reduce the number of vessels to be treated. ${ }^{39}$

This small exploratory study has many limitations, including the small number of patients and the lack of clinical follow-up. The inclusion of patients who had been referred for coronary angiography selected a population with a higher incidence of coronary heart disease and PAD. Therefore, these results, in a population of asymptomatic elderly patients, should be interpreted with caution. The finding that SS was consistent with the proper indication for percutaneous intervention, in a large proportion of patients, confirms previous clinical observations. However, its significance can only be affirmed in randomized studies specifically designed for this purpose.

\section{Conclusions}

Abnormal ABI is a marker of coronary complexity, even in high risk elderly patients. Similar frequencies of patients with $\mathrm{CAD}$, in the highest terciles of the SS, between those with, and without, abnormal ABI, are unexpected data, which should be explored in appropriately-sized studies.

\section{Disclosure}

The authors report no conflicts of interest in this work.

\section{References}

1. Selvin E, Erlinger TP. Prevalence of and risk factors for peripheral arterial disease in the United States: results from the National Health and Nutrition Examination Survey, 1999-2000. Circulation. 2004;110(6): 738-743.

2. Panico MDB, Spichler ES, Neves MF, Pinto LW, Spichler D. Prevalence and risk factors of symptomatic and asymptomatic peripheral arterial disease in a tertiary care hospital, Rio de Janeiro, Brazil. J Vasc Bras. 2009;8(2):125-132.

3. Aboyans V, Criqui MH, Abraham P, et al. Measurement and interpretation of the ankle-brachial index: a scientific statement from the American Heart Association. Circulation. 2012;126(24):2890-2909.

4. Zheng ZJ, Sharrett AR, Chambless LE, et al. Associations of anklebrachial index with clinical coronary heart disease, stroke and preclinical carotid and popliteal atherosclerosis: the Atherosclerosis Risk in Communities (ARIC) Study. Atherosclerosis. 1997;131(1):115-125.
5. Newman AB, Siscovick DS, Manolio TA, et al. Ankle-arm index as a marker of atherosclerosis in the Cardiovascular Health Study. Cardiovascular Heart Study (CHS) Collaborative Research Group. Circulation. 1993;88(3):837-845.

6. Newman AB, Shemanski L, Manolio TA, et al. Ankle-arm index as a predictor of cardiovascular disease and mortality in the Cardiovascular Health Study. The Cardiovascular Health Study Group. Arterioscler Thromb Vasc Biol. 1999;19(3):538-545.

7. Hirsch AT, Criqui MH, Treat-Jacobson D, et al. Peripheral arterial disease detection, awareness, and treatment in primary care. JAMA. 2001;286(11):1317-1324.

8. Papa EDE, Helber I, Ehrlichmann MR, et al. Ankle-brachial index as a predictor of coronary disease events in elderly submitted to coronary angiography. Clinics. In press 2013.

9. Rooke TW, Hirsch AT, Misra S, et al. 2011 ACCF/AHA Focused Update of the Guideline for the Management of Patients with Peripheral Artery Disease (updating the 2005 guideline): a report of the American College of Cardiology Foundation/American Heart Association Task Force on Practice Guidelines. J Am Coll Cardiol. 2011;58(19):2020-2045.

10. Hussein AA, Uno K, Wolski K, et al. Peripheral arterial disease and progression of coronary atherosclerosis. J Am Coll Cardiol. 2011; 57(10):1220-1225.

11. Papamichael CM, Lekakis JP, Stamatelopoulos KS, et al. Ankle-brachial index as a predictor of the extent of coronary atherosclerosis and cardiovascular events in patients with coronary artery disease. Am J Cardiol. 2000;86(6):615-618.

12. Núñez D, Morillas $P$, Quiles J, et al. Usefulness of an abnormal ankle-brachial index for detecting multivessel coronary disease in patients with acute coronary syndrome. Rev Esp Cardiol. 2010;63(1): 54-59.

13. Alderman EL, Stadius M. The angiographic definitions of the bypass angioplasty revascularization investigation. Coronary Artery Dis. 1992;3(12):1189-1208.

14. Krone RJ, Laskey WK, Johnson C, et al. A simplified lesion classification for predicting success and complications of coronary angioplasty. Registry Committee of the Society for Cardiac Angiography and Intervention. Am J Cardiol. 2000;85(10):1179-1184.

15. Califf RM, Phillips HR 3rd, Hindman MC, et al. Prognostic value of a coronary artery jeopardy score. J Am Coll Cardiol. 1985;5(5): 1055-1063.

16. Serruys PW, Morice M-C, Kappetein AP, et al. Percutaneous coronary intervention versus coronary-artery bypass grafting for severe coronary artery disease. New Engl J Med. 2009;360(10):961-972.

17. Schröder F, Diehm N, Kareem S, et al. A modified calculation of ankle-brachial pressure index is far more sensitive in the detection of peripheral arterial disease. J Vasc Surg. 2006;44(3):531-536.

18. European Stroke Organisation; Tendera M, Aboyans V, Bartelink ML, et al. ESC Guidelines on the diagnosis and treatment of peripheral artery diseases: Document covering atherosclerotic disease of extracranial carotid and vertebral, mesenteric, renal, upper and lower extremity arteries: the Task Force on the Diagnosis and Treatment of of Peripheral Artery Diseases of the European Society of Cardiology (ESC). Eur Heart J. 2011;32(22):2851-2906.

19. Smith SC, Dove JT, Jacobs AK, et al. ACC/AHA guidelines for percutaneous coronary intervention (revision of the 1993 PTCA guidelines)-executive summary: a report of the American College of Cardiology/American Heart Association task force on practice guidelines (Committee to revise the 1993 guidelines for percutaneous transluminal coronary angioplasty) endorsed by the Society for Cardiac Angiography and Interventions. Circulation. 2001;103(24):3019-3041.

20. Wykrzykowska JJ, Garg S, Girasis C, et al. Value of the SYNTAX score for risk assessment in the all-comers population of the randomized multicenter LEADERS (Limus Eluted from A Durable versus ERodable Stent coating) trial. J Am Coll Cardiol. 2010;56(4):272-277.

21. Silber S, Windecker S, Vranckx P, Serruys PW. Unrestricted randomised use of two new generation drug-eluting coronary stents: 2-year patientrelated versus stent-related outcomes from the RESOLUTE All Comers trial. Lancet. 2011;377(9773):1241-1247. 
22. Palmerini T, Genereux P, Caixeta A, et al. Prognostic value of the SYNTAX score in patients with acute coronary syndromes undergoing percutaneous coronary intervention: analysis from the ACUITY (Acute Catheterization and Urgent Intervention Triage StrategY) trial. J Am Coll Cardiol. 2011;57(24):2389-2397.

23. Meneghelo RS, Araújo CGS, Stein R, et al. III Diretrizes da Sociedade Brasileira de Cardiologia sobre Teste Ergométrico [III Guidelines of Sociedade Brasileira de Cardiologia on the exercise test]. Arq Bras Cardiol. 2010;95(5 Suppl 1):1-26. Portugese.

24. Den Ruijter HM, Vaartjes I, Sutton-Tyrrell K, Bots ML, Koffijberg H. Long-term health benefits and costs of measurement of carotid intimamedia thickness in prevention of coronary heart disease. J Hypertens. 2013;31(4):782-790.

25. Irie Y, Katakami N, Kaneto H, et al. The utility of carotid ultrasonography in identifying severe coronary artery disease in asymptomatic type 2 diabetic patients without history of coronary artery disease. Diabetes Care. 2013;36(5):1327-1334.

26. Polonsky TS, McClelland RL, Jorgensen NW, et al. Coronary artery calcium score and risk classification for coronary heart disease prediction. JAMA. 2010;303(16):1610-1616.

27. Makdisse M, Ramos LR, Moreira F, et al. Escore para rastrear idosos ( $>75$ anos) de alto risco para doença arterial periférica [A risk score for predicting peripheral arterial disease in individuals 75 years or older]. Arq Bras Cardiol. 2007;88(6):630-636. Portugese.

28. Moussa ID, Jaff MR, Mehran R, et al. Prevalence and prediction of previously unrecognized peripheral arterial disease in patients with coronary artery disease: the Peripheral Arterial Disease in Interventional Patients Study. Catheter Cardiovasc Interv. 2009;73(6):719-724.

29. Leng GC, Lee AJ, Fowkes FG, et al. Incidence, natural history and cardiovascular events in symptomatic and asymptomatic peripheral arterial disease in the general population. Int J Epidemiol. 1996;25(6): 1172-1181.

30. Källerö KS. Mortality and morbidity in patients with intermittent claudication as defined by venous occlusion plethysmography. A tenyear follow-up study. J Chronic Dis. 1981;34(9-10):455-462.
31. Narins CR, Zareba W, Moss AJ, et al. Relationship between intermittent claudication, inflammation, thrombosis, and recurrent cardiac events among survivors of myocardial infarction. Arch Intern Med. 2004;164(4):440-446.

32. Ogren M, Hedblad B, Engström G, Janzon L. Prevalence and prognostic significance of asymptomatic peripheral arterial disease in 68 -year-old men with diabetes. Results from the population study "Men born in 1914" from Malmö, Sweden. Eur J Vasc Endovasc Surg. 2005;29(2):182-189.

33. Heart Protection Study Collaborative Group. MRC/BHF Heart Protection Study of cholesterol lowering with simvastatin in 20,536 high-risk individuals: a randomised placebo-controlled trial. Lancet. 2002;360(9326):7-22.

34. Wykrzykowska JJ, Garg S, Onuma Y, et al. Implantation of the biodegradable polymer biolimus-eluting stent in patients with high SYNTAX score is associated with decreased cardiac mortality compared to a permanent polymer sirolimus-eluting stent: two year follow-up results from the "all-comers" LEADERS trial. EuroIntervention. 2011;7(5):605-613.

35. Korkmaz L, Adar A, Erkan H, et al. Ankle-brachial index and coronary artery lesion complexity in patients with acute coronary syndromes. Angiology. 2012;63(7):495-499.

36. Ikeda N, Kogame N, Iijima R, Nakamura M, Sugi K. Impact of carotid artery ultrasound and ankle-brachial index on prediction of severity of SYNTAX score. Circ J. 2013;77(3):712-716.

37. Benyakorn T, Kuanprasert S, Rerkasem K. A correlation study between ankle brachial pressure index and the severity of coronary artery disease. Int J Low Extrem Wounds. 2012;11(2):120-123.

38. Fokkema ML, James SK, Albertsson P, et al. Population trends in percutaneous coronary intervention: 20-year results from the SCAAR (Swedish Coronary Angiography and Angioplasty Registry). J Am Coll Cardiol. 2013;61(12):1222-1230.

39. De Bruyne B, Pijls NHJ, Kalesan B, et al. Fractional flow reserve-guided PCI versus medical therapy in stable coronary disease. New Engl J Med. 2012;367(11):991-1001.
Clinical Interventions in Aging

\section{Publish your work in this journal}

Clinical Interventions in Aging is an international, peer-reviewed journal focusing on evidence-based reports on the value or lack thereof of treatments intended to prevent or delay the onset of maladaptive correlates of aging in human beings. This journal is indexed on PubMed Central, MedLine, the American Chemical Society's 'Chemical Abstracts

\section{Dovepress}

Service' (CAS), Scopus and the Elsevier Bibliographic databases. The manuscript management system is completely online and includes a very quick and fair peer-review system, which is all easy to use. Visit http://www.dovepress.com/testimonials.php to read real quotes from published authors. 